\title{
Self-expandable metallic stents (SEMS) in esophageal varices post-band ulcer refractory bleeding: a retrospective study
}

\author{
Osama Elbahr ${ }^{1 *}$ D, Ahmad Kamal', Ayman Alsebaey', Mohamed Amin ${ }^{1}$, Mohamed Abbasy ${ }^{1}$, Ahmad Edris ${ }^{1}$, \\ Ali Nada ${ }^{1}$, Alyaa Sabry ${ }^{1}$, Sameh Afiffy ${ }^{1}$, Abd El-Aleem Helal ${ }^{1}$, Mohamad Abd El-aziz ${ }^{2}$ and Abd El-naser Gad-Allah ${ }^{3}$
}

\begin{abstract}
Background: Post-variceal band ligation bleeding ulcer is a severe complication with considerable mortality. We tried evaluating self-expandable metallic stent (SEMS) with concern to the ulcer morphology not well studied.

Results: We did a retrospective analysis of patients with bleeding post-band ulcers and treated by SEMS with concern to control bleeding and 6 weeks survival. Twenty-eight patients studied had their age (mean \pm S.D.) $57.8 \pm$ 8.6 years, and $85.7 \%$ were males. The Child-Pugh score range was $5-12$ ]. Control of bleeding by SEMS was achieved in 23 (82.1\%) patients, and overall, 6-week survival was 75\%. Both post-band ulcer types B (oozing blood and type C (active spurted) were a risk for 6 weeks mortality ( $P=0.04$, OR 1.58, Cl 95\% 1.12-2.23).
\end{abstract}

Conclusion: SEMS is considered an excellent choice to control esophageal post-banding ulcer bleeding and a definite treatment bridge.

Keywords: Liver cirrhosis, Portal hypertension, Varices, Post-band ulcer, Metallic stents, Bleeding

\section{Background}

Liver cirrhosis is a consequence of multiple etiologies that affect the liver. Chronic hepatitis $\mathrm{C}$ [1] and $\mathrm{B}$ viruses, non-alcoholic steatohepatitis, and alcoholic steatohepatitis are the most common leading causes of cirrhosis [2]. Patients with liver cirrhosis are classified into compensated or decompensated cirrhosis, according to Child-Pugh classification [3]. Further staging of cirrhosis depends on the development of varices, variceal bleeding, jaundice, hepatic encephalopathy, and ascites' development. The previous staging is the clinical presentation of portal hypertension that developed because of liver cirrhosis [4].

Esophageal varices are portosystemic venous channels and present in about half of patients diagnosed with cirrhosis. When portal pressure elevated to be clinically

\footnotetext{
* Correspondence: osama.elbahr@liver.menofia.edu.eg; oelbahr@yahoo.com ${ }^{1}$ Hepatology and Gastroenterology Department, National Liver Institute, Menoufia University, Shebin Alkawm, Menoufia, Egypt

Full list of author information is available at the end of the article
}

significant (hepatic vein portal gradient [HPVG] $>10$ $\mathrm{mmHg}$ ), portosystemic collaterals develop [5]. They at first create as little varices that continuously expand at a pace of $5 \%$ every year [6]. Screening for varices is an essential step in patients diagnosed with cirrhosis, and upper gastrointestinal endoscopy is the procedure of choice for defining, typing, and grading varices. Prophylaxis from 1st esophageal varices bleeding is achieved by either varices band ligation or non-selective beta-blocker administration [5, 7].

Acute variceal bleeding (AVB) is a well-known dangerous inconvenience in patients with cirrhosis. Current standard-of-care treatment incorporates the blend of vasoactive medications, band ligation, and anti-infection agents [8]. Endoscopic variceal band ligation (EVL) and pharmacological therapy for active esophageal variceal hemorrhage remain the first-line therapy. In most cases, band ligation outcomes are excellent, offering high initial hemostasis levels, low rebleeding rates, minimal side effects, and increased survival compared to sclerotherapy. 
Variceal ligation using an endoscope of diagnostic size can monitor excessive variceal bleeding with bands on active varix [9]. After EVL, the ligature bands stay in place for a range of 3 to 7 days. An ulcer remains that heals within 2 to 3 weeks. The thrombus formation is incomplete when the ligature band sloughs off, postligation ulcer bleeding occurs. Overall, the risk of postEVL ulcer bleeding is 3.6 to $15 \%$ [5]. The placement of a transjugular intrahepatic portosystemic shunt (TIPS) is considered for patients with treatment failure or recurrent bleeding, but it is not applicable for all cases [10]. For $10-20 \%$ of cirrhotics refractory for medical and endoscopy therapy, alternative treatment options must mitigate the substantial morbidity and mortality associated with it [11]. Nevertheless, the 6-week mortality rate after an E.V. bleed index is approximately $20 \%$. However, it varies from $0 \%$ among patients with Child-Pugh class A to roughly $30 \%$ among patients with Child-Pugh C disease [12].

Years ago, self-expanding metal stents (SEMS) were proposed in palliation for esophageal malignancy [13]. The fully covered SEMS is considered a rescue therapy in patients with refractory esophageal variceal bleeding. These stents can be deployed endoscopically in the lower esophagus with or without radiological assistance and easily removed later [14-16].

\section{Methods}

A retrospective study conducted on 28 patients with refractory bleeding post-band ulcers admitted to a specialized tertiary center (Hepatology and Gastroenterology Department), National Liver Institute, Menuofia University, Egypt, who received fully covered self-expandable metallic stents (FCSEMS) (NITI-S Mega stents-Tae Wong-S Korea) as a management of their refractory bleeding from post-variceal band ligation ulcer between January 2017 and December 2018.

During these 2 years, 1324 cases of hematemesis were admitted to our hospital, and 1096 cases had portal hypertensive cause of bleeding, and 612 had esophageal varices bleeding.

Prior endoscopic band ligation (EBL) treatments in the emergency setting, laboratory parameters, size of varices, and the bleeding episodes were recorded. The ChildPugh score, MELD, MELD-Na, and ALBI were calculated. Rebleeding rates and mortality after SEMS placement were defined as primary efficacy endpoints within 6 weeks. Moreover, adverse events and the patients' clinical course were recorded. We recorded rates of successful bleeding control ( $\leq 5$ days), early rebleeding $(\leq 6$ weeks), bleeding-related mortality ( $\leq 6$ weeks), and overall mortality. Successful SEMS removal was defined as no rebleeding or death within 1 day after stent removal. Refractory acute variceal bleeding (failure-to-control bleeding) with vasoactive drugs and endoscopy was defined according to the Baveno IV and V guidelines [17, 18]: fresh hematemesis or aspiration of more than $100 \mathrm{~mL}$ of new blood via the nasogastric tube beyond $2 \mathrm{~h}$ after the endoscopy and a $3 \mathrm{~g} / \mathrm{dL}$ drop in hemoglobin without blood transfusion. According to the Baveno $\mathrm{V}$ guidelines, rebleeding was defined as evidence of rebleeding from portal hypertensive sources (hematemesis, melaena, aspiration of more than $100 \mathrm{~mL}$ of fresh blood in patients with a nasogastric tube or drop in hemoglobin of $3 \mathrm{~g} / \mathrm{dL}$ without blood transfusion) $[17,18]$.

We classified post-banding ulcer endoscopically into (A) ulcer covered with clot; (B) ulcer oozing with blood; and $(\mathrm{C})$ ulcer actively spurting.

We excluded patients with age $<18$ years, intermediate and advanced HCC, the simultaneous presence of fundal varices, and previous attempts for balloon tamponade (B.T.) by sungestaken tube insertion management for refractory bleeding.

\section{The technique of stent deployment}

After sedation and adequate airway protection, the patient was placed in the left lateral position, the endoscope was passed into the esophagus, and a guidewire (0.035-in.) was established. The SEMS was loaded onto the guidewire and passed under fluoroscopic guidance. The radiopaque markers were helpful in the accurate positioning of the stent. Oral feeds with a liquid diet were started $12-24 \mathrm{~h}$ after the procedure, and patients were positioned at $45^{\circ}$ in a supine position for 1 day.

No informed consent has been obtained in this retrospective study.

This study was conducted under the Declaration of Helsinki and approved by the ethics committees of our IRB.

\section{Calculations}

From online calculators

Child-Pugh

https://www.mdcalc.com/child-pugh-score-cirrhosismortality

ALBI

https://www.mdcalc.com/albi-albumin-bilirubin-gradehepatocellular-carcinoma-hcc

MELD

https://www.mdcalc.com/meld-score-original-pre-2 016-model-end-stage-liver-disease

\section{MELD-Na}

https://www.mdcalc.com/meldna-meld-na-score-livercirrhosis

\section{Statistical analysis}

Results were statistically analyzed using IBM SPSS version 21 for Windows. Variables were summarized as mean \pm S.D., range, median, or frequency 
(\%), as appropriate. Student's $t$ test was used to compare the results of all examined subjects in all groups under study. Odds ratio (OR) and 95\% confidence interval $(\mathrm{CI})$, and the chi-square test were used. Results were considered significant when $P \leq$ 0.05 .

Table 1 Demographic, clinical, and endoscopic characteristics of the patients:

\begin{tabular}{|c|c|c|}
\hline Characteristics & Range & \\
\hline Age, years (mean $\pm S D$ ) & $35-75$ & $56.6 \pm 9.4$ \\
\hline Gender (male) NO \% & & $24(85.7 \%)$ \\
\hline $\begin{array}{l}\text { Cirrhosis aetiology (HCV/HBV) NO } \\
\%\end{array}$ & & $24(85 / 7 \%) / 4$ \\
\hline Diabetes NO \% & & $13(46.4 \%)$ \\
\hline Hypertension NO \% & & $3(10.7 \%)$ \\
\hline Smokers NO \% & & $9(32.1 \%)$ \\
\hline HCC NO \% & & $5(17.85 \%)$ \\
\hline PVT NO \% & & $6(21.4 \%)$ \\
\hline SBP at admission & & $12(42.86 \%)$ \\
\hline CTP class (A/B/C) NO \% & & $\begin{array}{l}3(10.7 \%) / 15(53.6 \%) / 10 \\
(35.7 \%)\end{array}$ \\
\hline CTP score (mean \pm SD) & $5-12$ & $8.6 \pm 1.8 /$ median 8 \\
\hline MELD at admission (mean $\pm S D$ ) & $8-42$ & $15.7 \pm 6.3$ \\
\hline $\begin{array}{l}\text { MELD Na at admission (mean } \pm \\
\text { SD) }\end{array}$ & $10-42$ & $20 \pm 6.4$ \\
\hline $\mathrm{ALBl}$ at admission (mean $\pm \mathrm{SD}$ ) & $\begin{array}{l}-2.36 \text { to }- \\
0.14\end{array}$ & $-1.36 \pm 0.58$ \\
\hline $\begin{array}{l}\text { Post band bleeding presentation } \\
\text { time }\end{array}$ & $2-14$ days & Median 10 days \\
\hline $\begin{array}{l}\text { Mean blood pressure (mean } \pm \\
\text { SD) }\end{array}$ & $53-97$ & $75 \pm 10.8$ \\
\hline $\begin{array}{l}\text { Hemoglobin at admission } \mathrm{g} / \mathrm{dl} \\
(\text { mean } \pm \mathrm{SD})\end{array}$ & $6.2-13.2$ & $8.2 \pm 1.45$ \\
\hline Units of transfused blood (NO) & $0-16$ & Median 2 units \\
\hline \multicolumn{3}{|l|}{ Prophylactic antibiotics (NO) } \\
\hline - 3rd cephalosporins & & -18 \\
\hline - Quinolones & & -4 \\
\hline - combined & & -6 \\
\hline \multicolumn{3}{|l|}{ Portal decompressive drugs (NO) } \\
\hline - Sandostatin & & -14 \\
\hline - glypressin & & -14 \\
\hline OVs size (small:large) NO \% & & $\begin{array}{l}15(53.57 \%) / 13 \\
(46.43 \%)\end{array}$ \\
\hline \multicolumn{3}{|l|}{ Post band ulcer NO \% } \\
\hline - Type A & & $-9(32.14 \%)$ \\
\hline - Type B & & $-7(25 \%)$ \\
\hline - Type C & & $-12(42.86 \%)$ \\
\hline
\end{tabular}

\section{Results}

\section{Patients' characteristics}

From our data, esophageal variceal bleeding was $46 \%$ of all cases of hematemesis present in our department, and refractory bleeding post-variceal band ligation was $4 \%$ of variceal bleeding cases.

As presented in Table 1, 28 patients studied had their age (mean \pm S.D.) $57.8 \pm 8.6$ years, and $85.7 \%$ were males. Their Child score range 5-12 and the median was 8. Five patients had early-stage HCC. $21.4 \%$ of the patients had portal vein thrombosis (PVT). Patients presented with bleeding after previous band ligation either 1ry or 2ry prophylaxis for esophageal varices 2-14 days with 10 days median. On admission, their prognostic scores were MELD $15.7 \pm 6.3$, MELD Na $20 \pm 6.4$, and ALBI score $1.36 \pm 0.58$. Patients needed $0-16$ units of blood transfused with a mean of 2 units.

Bleeding post-banding ulcer (BPBU) classified endoscopically into (A) $32.14 \%$ ulcer covered with clot (9 patients); (B) 25\% ulcer oozing blood (7 patients); and (C) $42.86 \%$ ulcer with active spurting (12 patients).

\section{Post-SEMS placement outcomes (Table 2, Figs. 1 and 2, and Additional file 1)}

Regarding control of bleeding, 3 (10.7\%) patients had uncontrolled bleeding, despite stent insertion, and all died. Two patients experienced early rebleeding after

Table 2 Outcome data

\begin{tabular}{|c|c|}
\hline & $N(\%)$ \\
\hline \multicolumn{2}{|l|}{ Control of bleeding } \\
\hline Uncontrolled & 3 \\
\hline Re-bleeding & $\begin{array}{l}2 \text { (1 stent displaced-1 post- } \\
\text { stent removal) }\end{array}$ \\
\hline controlled & $23(82 \%)$ \\
\hline 6 weeks survival (deceased/alive) & $7 / 21(75 \%)$ \\
\hline Stent displaced & $\begin{array}{l}6(21.43 \%) \text { (1 re-stent and } 3 \\
\text { re-positioned) }\end{array}$ \\
\hline \multirow[t]{2}{*}{ Stent-related complications (no. 4) } & 2 aspiration \\
\hline & $\begin{array}{l}2 \text { aspiration } \\
\text { bronchopneumonia }\end{array}$ \\
\hline $\begin{array}{l}\text { Development of encephalopathy post- } \\
\text { endoscopy (no. 9) }\end{array}$ & $9(32.1 \%)$ \\
\hline Covert & 3 \\
\hline Overt & 6 \\
\hline \multicolumn{2}{|l|}{6 weeks cause related mortality (no. 7) } \\
\hline Bleeding & $4(14.3 \%)$ \\
\hline Sepsis & 1 \\
\hline MOF & 2 \\
\hline Rescue therapy & $\begin{array}{l}2 \text { sungestaken tubes (1 } \\
\text { deceased) }\end{array}$ \\
\hline
\end{tabular}



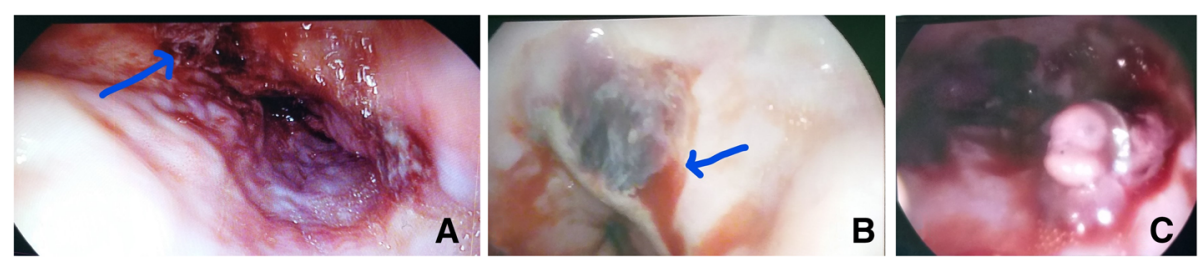

Fig. 1 a Type A ulcer with an adherent blood clot. b Type B ulcer with oozing blood. c Type C ulcer spurting blood

initial management. SEMS achieved bleeding control in $23(82.1 \%)$ patients. From all patients, for 42 days follow-up, $14.3 \%$ of patients died due to bleeding. The mean days of survival were 34 (CI 95\% 28-39) with 6 weeks survival 75\%. Six (21.4\%) patients' stents were displaced, and only one patient experienced rebleeding that was uncontrollable after sungestaken tube insertion, and he died. The others, one patient, undergone re-stenting, three stents repositioned, and one showed healed stable ulcers, so followed up. Successful stent removal was done in 20 (71.4\%) patients from 23 who survived. At the same time, one patient had rebleeding after stent removal controlled by sungestaken tube insertion. Nine patients (32.1\%) developed hepatic encephalopathy post-SEMS deployment. Two patients had aspirated, and another two patients developed aspiration pneumonia.

\section{Identified risk factors for 6 weeks mortality after SEMS deployment}

Univariate analysis was conducted (Tables 3 and 4) revealed that post-band ulcers other than type A, development of overt hepatic encephalopathy were a risk for 6 weeks mortality $(P=0.04,0.02$ respectively). Low baseline arterial blood pressure (65 \pm 6.7 , $P=0.003)$ and increased number of transfused blood units $(5.4 \pm 4.8, P=0.006)$ were associated with 6 weeks mortality.

\section{Discussion}

Current guidelines recommend either balloon tamponade (B.T.), SEMS, or TIPS to manage refractory and endoscopically uncontrolled variceal bleeding [11, 19]. Nevertheless, the evaluation of SEMS in refractory bleeding post-band ulcers concerning ulcer morphology was not well studied.

In our study, we had a high rate of successful bleeding control in $82 \%$ of patients. Our rebleeding rate was so low that only one patient due to stent displacement and another after stent removal. A meta-analysis comprising $n=134$ showed a failure-to-control bleeding rate of $14.2 \%$ [8]. Pfisterer and colleagues showed $1 / 3$ of their cases achieved control of bleeding in their follow-up period. Also, they showed a higher overall rate of rebleeding, especially after stent removal (about 29.4\%) [19]. In the previously mentioned meta-analysis, postSEMS removal bleeding was $11 \%$ [8]. Another metaanalysis showed rebleeding rate was $13.2 \%$ [6]. This difference could be attributed to the type and diameter of SEMS used. In our study, a mega stent with a diameter of $28 \mathrm{~mm}$ that is fitting well on the esophageal wall.

Pfisterer stated that "bleeding-related mortality was as high as $47.1 \%$ ( $n=16 / 34)$ of patients in our study, including $20.6 \%(n=7 / 34)$ who deceased owing to uncontrolled bleeding" [19]. In our retrospective analysis, bleeding-related mortality was very low, $14.3(n=4 / 28)$, and this agrees with two recent meta-analyses, the first found $12 \%$ for mortality related to variceal bleeding, and
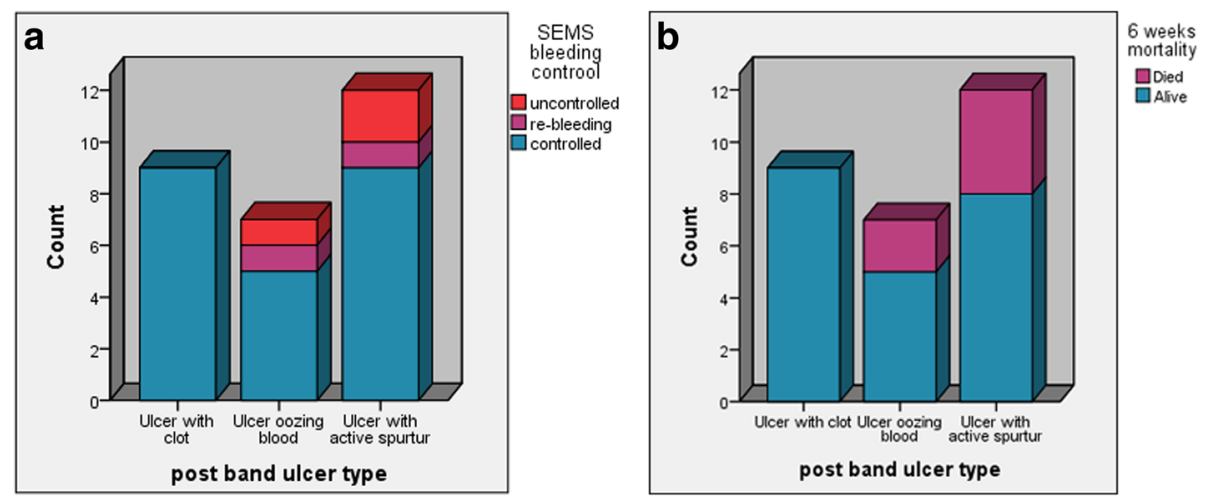

Fig. 2 a Control of bleeding. b Mortality after SEMS deployment according to ulcer type 
Table 3 Univariate analysis for mortality 6 weeks follow-up

\begin{tabular}{|c|c|c|c|c|c|}
\hline & $\begin{array}{l}6 \text { weeks mortality } \\
\text { Dead } 7\end{array}$ & $\begin{array}{l}6 \text { weeks mortality } \\
\text { Alive } 21\end{array}$ & Test & $P$ value & $\mathrm{Cl} 95 \%$ \\
\hline Age, years & $55.8 \pm 10.38$ & $58.5 \pm 8.2$ & $\begin{array}{l}T \\
-0.68\end{array}$ & 0.5 & $(-10.45-5.2)$ \\
\hline CTP score & $8.7 \pm 1.8$ & $8.5 \pm 1.8$ & $\begin{array}{l}T \\
0.17\end{array}$ & 0.86 & $(-1.5-1.8)$ \\
\hline MELD at admission & $17.14 \pm 11.45$ & $15.24 \pm 3.72$ & $\begin{array}{l}T \\
2.8\end{array}$ & $0.008^{*}$ & $(-3.8-7.6)$ \\
\hline MELD Na at admission & $22.86 \pm 9.65$ & $19.05 \pm 4.9$ & $\begin{array}{l}T \\
3.1\end{array}$ & $0.004^{* *}$ & $(-1.85-9.47)$ \\
\hline Hemoglobin on admission $\mathrm{g} / \mathrm{dl}$ & $7.8 \pm 1.2$ & $8.4 \pm 1.5$ & $\begin{array}{l}T \\
-0.84\end{array}$ & 0.4 & $(-1.85-0.77)$ \\
\hline Mean blood pressure on admission & $65.14 \pm 6.74$ & $78.3 \pm 9.88$ & $\begin{array}{l}T \\
-3.2\end{array}$ & $0.003^{* * *}$ & $(-21.5$ to -4.5$)$ \\
\hline UNITS of blood & $5.4 \pm 4.8$ & $2 \pm 1.5$ & $\begin{array}{l}T \\
2.9\end{array}$ & $0.006^{* * *}$ & $(1.05-5.8)$ \\
\hline ALBI & $-1.16 \pm 0.69$ & $-1.42 \pm 0.54$ & $\begin{array}{l}T \\
1.03\end{array}$ & 0.3 & $(-0.25-0.77)$ \\
\hline
\end{tabular}

$18 \%$ for failure to control bleeding with SEMS [8], and the second found $12.6 \%$ of patients died from uncontrolled bleeding [6]. We think the possible explanation for this with our results is selecting patients with postband ulcers only in our study.

A multicenter trial compared SEMS with balloon tamponade (B.T.) in a series of cirrhotic patients with variceal bleeding. This study showed a superior safety profile and higher efficacy in controlling bleeding with SEMS. However, the use of SEMS did not result in improved survival [20]. They had no patients who developed aspiration and aspiration pneumonia in the SEMS group. Still, in our study, we had two patients who had aspiration and another two who developed pneumonia, which could be due to the low number of participants in the Escorsell study $(n=13)$ [20].

Stent dislocations were found in $n=13$ (38.2\%) patients in Pfisterer study 2019. In our analysis, it was $n=$ $6(21.43 \%)$ patients. In a meta-analysis, the incidence of stent migration was $21.6 \%$ [6]. The different types and diameters of SEMS used in the study may be the explanation for this difference.

Six weeks of survival in our study was $75 \%(n=21)$. In the Spanish clinical trial study, the survival was $54 \%$, which is not different from the B.T. group 40\% [20]. $47.1 \%$ of patients died within 6 weeks due to bleedingrelated complications in Pfisterer study [19]. Pooled 30day and 60-day survival rates were $68 \%$ and $64 \%$, respectively, in a meta-analysis [11].

No previous studies specified post-band ulcer bleeding in their analysis and respect to the ulcers' morphology. In our research, the ulcer type has a significant impact on rebleeding and mortality after SEMS insertion. As we have all type A (ulcer with clot) patients that had $100 \%$ for both bleeding control and 6 weeks survival. So, we think the ulcer type can guide the intervention modality to be used. Jamwal and colleagues tried in their retrospective study to evaluate the impact of the morphology

Table 4 Clinical data related to 6 weeks mortality

\begin{tabular}{|c|c|c|c|c|c|c|c|c|c|}
\hline \multirow[b]{2}{*}{$\mathrm{HCC}$} & \multirow[b]{2}{*}{ Yes } & \multicolumn{2}{|c|}{$\begin{array}{l}6 \text { weeks mortality } \\
\text { Dead } 7\end{array}$} & \multicolumn{2}{|c|}{$\begin{array}{l}6 \text { weeks mortality } \\
\text { Alive } 21\end{array}$} & \multirow{3}{*}{$\begin{array}{l}\text { Test } \\
\text { Fisher } \\
0.7\end{array}$} & \multirow{2}{*}{$\begin{array}{l}\boldsymbol{P} \text { value } \\
0.57\end{array}$} & \multirow[t]{2}{*}{ Odd's ratio } & \multirow[t]{2}{*}{$\mathrm{Cl} 95 \%$} \\
\hline & & 2 & $40 \%$ & 3 & $60 \%$ & & & & \\
\hline No & 5 & $21.7 \%$ & 18 & $78.3 \%$ & & & & & \\
\hline \multirow[t]{2}{*}{ SBP } & Yes & 3 & $25 \%$ & 9 & $75 \%$ & \multirow{2}{*}{$\begin{array}{l}x^{2} \\
0.00\end{array}$} & \multirow[t]{2}{*}{0.6} & & \\
\hline & No & 4 & $25 \%$ & 12 & $75 \%$ & & & & \\
\hline \multirow[t]{2}{*}{ Post-band ulcer } & Type A & 0 & $0 \%$ & 9 & $100 \%$ & \multirow{2}{*}{$\begin{array}{l}x^{2} \\
4.4\end{array}$} & \multirow[t]{2}{*}{$0.043^{*}$} & \multirow[t]{2}{*}{1.58} & \multirow[t]{2}{*}{$(1.12-2.23)$} \\
\hline & Type (B and C) & 7 & $36.8 \%$ & 12 & $63.2 \%$ & & & & \\
\hline \multirow[t]{2}{*}{ Encephalopathy } & Overt & 4 & $66.7 \%$ & 2 & $33.3 \%$ & \multirow{2}{*}{$\begin{array}{l}x^{2} \\
7\end{array}$} & \multirow[t]{2}{*}{$0.02^{*}$} & \multirow[t]{2}{*}{2.59} & \multirow[t]{2}{*}{$(0.8-8.1)$} \\
\hline & Covert & 3 & $13.6 \%$ & 19 & $86.4 \%$ & & & & \\
\hline
\end{tabular}


of post-band bleeding ulcers on the choice of treatment options, and they found that ulcers with clots could have a favorable outcome with repeated banding or SEMS insertion according to Child-Pugh class [21].

The most important limitation of our study is its uncontrolled retrospective design and the low number of cases.

\section{Conclusion}

SEMS is a very effective strategy when used appropriately in post-band ulcer bleeding. We should take into consideration the morphological picture of the ulcer and the general condition of the patient. So, we can get a high rate of bleeding control and survival benefits.

\begin{abstract}
Abbreviations
SEMS: Self-expandable metallic stents; AVB: Acute variceal bleeding; HPVG: Hepatic vein portal gradient; EVL or EBL: Endoscopic variceal band ligation; TIPS: Transjugular intrahepatic portosystemic shunt; B.T.: Balloon tamponade; HCC: Hepato-cellular carcinoma; PVT: Portal vein thrombosis; MELD: Model of end-stage liver disease
\end{abstract}

\section{Supplementary Information}

The online version contains supplementary material available at https://doi. org/10.1186/s43066-021-00100-z.

Additional file 1. Study flowchart.

\section{Acknowledgements}

The authors thank and acknowledge the endoscopy unit's role at the National Liver Institute, Menoufia University.

\section{Authors' contributions \\ O.E.: data collection, endoscopist, statistical analysis, manuscript writing, AK: endoscopist, data collection, A.A.: endoscopist, manuscript writing, MA: endoscopist, data collection, MA: endoscopist, manuscript writing, A.E.: endoscopist, data collection, AIN: endoscopist, data collection, AS: endoscopist, data collection, S.A.: endoscopist, data collection, A.H.: data collection, MAE: endoscopist, data collection, AG: endoscopist, data collection. All authors have read and approved the final manuscript.}

\section{Funding}

No funding was received.

\section{Availability of data and materials}

Available from the corresponding author.

\section{Declarations}

\section{Ethics approval and consent to participate}

The Research Ethics Committee approved the study of our medical institute (National Liver Institute IRB00003621). All study procedures were carried out per the Declaration of Helsinki regarding research involving human subjects. Every patient filled a written consent form after a detailed explanation of the study and management plan.

\section{Consent for publication}

N/A.

\section{Competing interests}

The authors declare that they have no competing interests.

\section{Author details}

'Hepatology and Gastroenterology Department, National Liver Institute, Menoufia University, Shebin Alkawm, Menoufia, Egypt. ${ }^{2}$ Internal medicine department, Alexandria University, Alexandria, Egypt. ${ }^{3}$ Internal Medicine Department, Menoufia University, One, Meleeg Road, National liver Institute, Shebin Alkawm, Menoufia, Egypt.

Received: 10 December 2020 Accepted: 21 April 2021

Published online: 05 May 2021

\section{References}

1. Elbahr O, Saleh AA, Bakery LH (2020) PNPLA3 L148M (rs738409) polymorphism as a risk for new onset diabetes mellitus and obesity in non$\mathrm{NASH} / \mathrm{cryptogenic}$ living related donor liver transplant recipients. Gene Rep. 19:100607. https://doi.org/10.1016/j.genrep.2020.100607

2. Wiegand J, Berg T (2013) The etiology, diagnosis and prevention of liver cirrhosis: part 1 of a series on liver cirrhosis. Dtsch Arztebl Int. 110(6):85-91. https://doi.org/10.3238/arztebl.2013.0085

3. Ginés P, Quintero E, Arroyo V, Terés J, Bruguera M, Rimola A, Caballería J, Rodés J, Rozman C (1987) Compensated cirrhosis: natural history and prognostic factors. Hepatology. 7(1):122-128. https://doi.org/10.1002/hep.1 840070124

4. D'Amico G, Garcia-Tsao G, Pagliaro L (2006) Natural history and prognostic indicators of survival in cirrhosis: a systematic review of 118 studies. J Hepatol. 44(1):217-231. https://doi.org/10.1016/j.jhep.2005.10.013

5. Nett A, Binmoeller KF (2019) Endoscopic management of portal hypertension-related bleeding. Gastrointest Endosc Clin N Am. 29(2):321337. https://doi.org/10.1016/j.giec.2018.12.006

6. Shao X-D, Qi X-S, Guo X-Z (2016) Esophageal stent for refractory variceal bleeding: a systemic review and meta-analysis. Biomed Res Int. 2016: 4054513-4054510. https://doi.org/10.1155/2016/4054513

7. Bunchorntavakul C, Reddy KR (2019) Pharmacologic management of portal hypertension. https://doi.org/10.1016/j.cld.2019.06.004

8. Marot A, Trepo E, Doerig C, Moreno C, Moradpour D, Deltenre P (2015) Systematic review with meta-analysis: self-expanding metal stents in patients with cirrhosis and severe or refractory oesophageal variceal bleeding. Aliment Pharmacol Ther. 42(11-12):1250-1260. https://doi.org/1 0.1111/apt.13424

9. Kovacs TOG, Jensen DM (2019) Varices: esophageal, gastric, and rectal. Clin Liver Dis. 23(4):625-642. https://doi.org/10.1016/j.cld.2019.07.005

10. Fortune B, Garcia-Tsao G (2014) Current management strategies for acute esophageal variceal hemorrhage. Curr Hepatol Rep. 13(1):35-42. https://doi. org/10.1007/s11901-014-0221-y

11. McCarty TR, Njei B (2016) Self-expanding metal stents for acute refractory esophageal variceal bleeding: a systematic review and meta-analysis. Dig Endosc. 28(5):539-547. https://doi.org/10.1111/den.12626

12. Kovacs TOG, Jensen DM Varices esophageal, gastric, and rectal. https://doi. org/10.1016/j.cld.2019.07.005

13. Elbahr O, Kamal A, Amin M, et al. Cronicon EC GASTROENTEROLOGY AND DIGESTIVE SYSTEM Evaluation of Self Expandable Metal Stents (SEMS) in Upper Gastrointestinal Malignancies as a Palliative Treatment, a Single Center Experience "Evaluation of Self Expandable Metal Stents (SEMS) in Upper Gastrointestinal Malignancies as a Palliative Treatment, a Single Center Experience". EC Gastroenterology and Digestive System 5.4 (2018): 204-210:; 2018.

14. Zehetner J, Shamiyeh A, Wayand W, Hubmann R (2008) Results of a new method to stop acute bleeding from esophageal varices: implantation of a self-expanding stent. Surg Endosc Other Interv Tech. 22(10):2149-2152. https://doi.org/10.1007/s00464-008-0009-7

15. Hubmann R, Bodlaj G, Czompo M, Benkö L, Pichler P, al-Kathib S, Kiblböck P, Shamyieh A, Biesenbach G (2006) The use of self-expanding metal stents to treat acute esophageal variceal bleeding. Endoscopy. 38(9):896-901. https:// doi.org/10.1055/s-2006-944662

16. Elbahr O, Kamal A, Alsebaey A et al (2019) Self-expandable metallic stents (SEMS) in esophageal varices post band ulcer refractory bleeding, a retrospective study. In: ESGE Days 2019, vol 51. Georg Thieme Verlag KG. https://doi.org/10.1055/s-0039-1681881

17. De Franchis R (2005) Evolving consensus in portal hypertension report of the Baveno IV Consensus Workshop on methodology of diagnosis and therapy in portal hypertension. J Hepatol. 43(1):167-176. https://doi.org/10.1 016/j.jhep.2005.05.009

18. De Franchis R (2010) Revising consensus in portal hypertension: report of the Baveno $V$ consensus workshop on methodology of diagnosis and therapy in portal hypertension. https://doi.org/10.1016/j.jhep.2010.06.004 
19. Pfisterer N, Riedl F, Pachofszky T, Gschwantler M, König K, Schuster B, Mandorfer M, Gessl I, Illiasch C, Fuchs EM, Unger L, Dolak W, Maieron A, Kramer L, Madl C, Trauner M, Reiberger T (2019) Outcomes after placement of a SX-ELLA oesophageal stent for refractory variceal bleeding - a national multicentre study. Liver Int. 39(2):290-298. https://doi.org/10.1111/liv.13971

20. Escorsell A, Pavel O, Cardenas A et al (2016) Esophageal balloon tamponade versus esophageal stent in controlling acute refractory variceal bleeding: a multicenter randomized, controlled trial. Hepatology. 63(6):1957-1967. https://doi.org/10.1002/hep.28360

21. Jamwal KD, Maiwall R, Sharma MK, Kumar G, Sarin SK (2019) Case control study of post-endoscopic variceal ligation bleeding ulcers in severe liver disease: outcomes and management. https://doi.org/10.14218/JCTH.2018. 00059

\section{Publisher's Note}

Springer Nature remains neutral with regard to jurisdictional claims in published maps and institutional affiliations.

\section{Submit your manuscript to a SpringerOpen ${ }^{\circ}$ journal and benefit from:}

- Convenient online submission

- Rigorous peer review

- Open access: articles freely available online

High visibility within the field

- Retaining the copyright to your article

Submit your next manuscript at $\boldsymbol{\nabla}$ springeropen.com 